\title{
Oligoflexia, the Newest Class of the Phylum Proteobacteria, Consisting of only One Cultured Species and Uncultured Bacterial Phylotypes from Diverse Habitats
}

\section{Ryosuke Nakai ${ }^{1,2}$ and Takeshi Naganuma ${ }^{3^{*}}$}

${ }^{1}$ Genetic Strains Research Center, National Institute of Genetics, 1111 Yata, Mishima, Shizuoka, 411-8540, Japan

${ }^{2}$ Superlative Postdoctoral Research Fellow of the Japan Society for the Promotion of Science, Chiyoda-ku, Tokyo 102-8471, Japan

${ }^{3}$ Graduate School of Biosphere Science. Hiroshima University, 1-4-4 Kagamiyama, Higashi-hiroshima, Hiroshima 739-8528, Japan

\begin{abstract}
The phylum Proteobacteria has recently gained a new taxon Oligoflexia that represents the seventh or eighth (if yet-to-be-validated "Zetaproteobacteria" is included) class, described by the only cultured species (as of December 2014), Oligoflexus tunisiensis, as the type species. This bacterium exhibits cellular polymorphism and presence of the uncommon fatty acid $\mathrm{C} 16: 1 \omega 5 \mathrm{c}$ as high as $>65 \%$ of total fatty acids, besides its unique $16 \mathrm{~S}$ rRNA gene sequence. The class Oligoflexia is characterized by the distinct phylogenetic cluster within the greater proteobacterial cluster, and certain environmentally-derived 16S rRNA gene sequences, a.k.a. environmental clones or phylotypes, of uncultured bacteria are now grouped into the Oligoflexia cluster; however, the content and extent of the cluster has not been clearly depicted. This mini-review illustrates that the Oligoflexia cluster hosts a variety of environmental clones from diverse sources. Currently 20 phylotypes (or clones) are affiliated with the Oligoflexia cluster, and the sources were ranging from soils to cyanobacterial mat, bio-filter, human skin, ant colony, desert, glacial ice, earthworm intestine, and seawater. However, their frequencies in respective clone libraries were generally as low as $<1 \%$, which indicates their corresponding species are only minor in respective microbial communities. Moreover, 61 environmental metagenome libraries yielded only 1198 partial sequences having $>85 \%$ similarities (class-level affiliation) to the $16 \mathrm{~S}$ rRNA gene sequence of $O$. tunisiensis, which accounts for merely $0.04 \%$ of those registered in Meta-Metagenomic Data Base (MetaMeta DB). On the other hand, $>97 \%$-similarities sequences were found in rhizosphere, and $<95 \%$-similar sequences were found from hydrocarbon-rich habitats such as petroleum reservoir. Thus, it is suggested that members of Oligoflexia may display cosmopolite distribution in general as well as endemism in certain geochemical settings.
\end{abstract}

Keywords: Bacteria; Proteobacteria; Oligoflexia; Phylogeny; $16 \mathrm{~S}$ rRNA gene; Metagenome

\section{Introduction}

The largest eubacterial phylum Proteobacteria accommodates about 1600 bacterial species exhibiting extremely diversified morphologies (as expressed in its name as "Proteus"), phylogenies, and metabolisms relevant to geochemical cycling of carbon, nitrogen, sulphur, etc. [1]. The phylum Proteobacteria hosts the greatest number of "culturable" described and deposited species among the prokaryotic phyla $[1,2]$, while the phylum harbors numerous environmentally-derived $16 \mathrm{~S}$ rRNA gene sequences, a.k.a. environmental clones or phylotypes, of "uncultured" bacteria whose physiological properties are largely unknown $[3,4]$.

The proteobacterial taxa were formerly grouped as "purple bacteria" [5], then re-organized phylogenetically based on 16S rRNA gene sequences into five classes of Alphaproteobacteria, Betaproteobacteria, Gammaproteobacteria, Deltaproteobacteria and Epsilonproteobacteria [6] and, two more classes were proposed thereafter; they are yetto-be-validated 'Zetaproteobacteria' [7] and already-validated Acidithiobacillia [8] which is a revision of part of the species formerly affiliated with Gammaproteobacteria [8].

We have proposed the seventh or eighth class, if 'Zetaproteobacteria' is excluded or included, respectively, in the phylum Proteobacteria, with the description of the type species Oligoflexus tunisiensis [9] that is the only "cultured" species of the class currently. In proposing the new class, we have constructed a phylogenetic tree of the Oligoflexia cluster consisting of a number of environmental clones of uncultured bacteria from various sources. Thus, this mini-review discusses their environmental and geographical features as well as some unique properties of O. tunisiensis.

\section{Unique morphological and phenotypic traits of O. tunisiensis}

Sterile filtration has been a common technique to remove microorganisms from fluids in pharmaceutical and food industries as well as in many areas of biology. For sterilization purposes, membrane filters having a pore size of $0.2 \mu \mathrm{m}$ are generally used. Nevertheless, not all bacteria are trapped with the filters; certain novel taxa have been found in the $0.2 \mu \mathrm{m}$-filtrates $[10,11]$. Likewise, O. tunisiensis was first obtained from the $0.2 \mu \mathrm{m}$-filtrate of liquid suspended with Saharan sand and pebbles [9]. While the cells of $O$. tunisiensis indeed pass the $0.2 \mu \mathrm{m}$-filters, they also show polymorphism with filamentous, spiral, spherical, or curved rod shapes (Figure 1). Though factors controlling the cell shapes have been unclear, their morphological flexibility and versatility would be associated with the nature to pass through $0.2 \mu \mathrm{m}$ filters. Therefore, it is considered that our $0.2 \mu \mathrm{m}$-filtration was effective to remove fast-growers and preferably selective for slow-growing species. In addition, $O$. tunisiensis resumes growth when transferred to fresh agar plates from senile colonies as old as half a year (M. Nishijima, personal communication).

*Corresponding author: Takeshi Naganuma, Graduate School of Biosphere Science, Hiroshima University, 1-4-4 Kagamiyama, Higashi-hiroshima, Hiroshima 739-8528, Japan, Tel: 81-82-424-7986; Fax: 81-82-424-7916; E-mail: takn@ hiroshima-u.ac.jp

Received November 17, 2014; Accepted December 17, 2014; Published December 20, 2014

Citation: Nakai R, Naganuma T (2015) Oligoflexia, the Newest Class of the Phylum Proteobacteria, Consisting of only One Cultured Species and Uncultured Bacterial Phylotypes from Diverse Habitats. J Phylogen Evolution Biol 3: 141. doi:10.4172/2329-9002.1000141

Copyright: (c) 2015 Nakai R, Naganuma T. This is an open-access article distributed under the terms of the Creative Commons Attribution License, which permits unrestricted use, distribution, and reproduction in any medium, provided the original author and source are credited. 
Citation: Nakai R, Naganuma T (2015) Oligoflexia, the Newest Class of the Phylum Proteobacteria, Consisting of only One Cultured Species and Uncultured Bacterial Phylotypes from Diverse Habitats. J Phylogen Evolution Biol 3: 141. doi:10.4172/2329-9002.1000141

Physiological and biochemical properties of O. tunisiensis are listed in Table 1. This bacterium shows mesophilic and neutrophilic growth characteristics with optimum temperature and $\mathrm{pH}$ of $25-30^{\circ} \mathrm{C}$ and 7.0-8.0, respectively, as seen in many other bacterial species. In contrast, this bacterium has unique cellular fatty acid contents. More than $90 \%$ of total fatty acids is composed only of two fatty acids, C16: $1 \omega 5 \mathrm{c}(65.7 \%)$ and $\mathrm{C} 16: 0(27.5 \%)$, the former being rarely seen in other species [12,13]. It is unclear whether high content of C16: $1 \omega 5 \mathrm{c}$ would be general feature of the whole class Oligoflexia; this rare fatty acid could be taken as a biomarker at least of the species O. tunisiensis.

The C16: $1 \omega 5 \mathrm{c}$ fatty acid has also been detected in myxobacteria belonging to Deltaproteobacteria but to a lesser content of $15-39 \%$ (of total fatty acids) at most [13]. It was proposed to be a possible biomarker of microbial consortia responsible for anaerobic methane oxidation, or ANME, in methane-seeping marine sediments [14]. The ANME consortia are composed of archaea capable of reverse methanogenesis as anaerobic methane oxidizers and sulfate-reducing bacteria belonging to Deltaproteobacteria as potential hydrogendonors in the sediments [15]. About half of the sediment fatty acids is dominated by various C16: 1 acids, most of which is due to C16: $1 \omega 5 \mathrm{c}$ probably from bacterial part of the consortia [14]. In O. tunisiensis, C16: $1 \omega 5 \mathrm{c}$ solely accounts for $65.7 \%$ of total fatty acids, and thus should serve as a useful biomarker.

\section{Not-yet-cultured bacteria within the class Oligoflexia}

In the phylogenetic tree of the phylum Proteobacteria depicted in Nakai et al. [9], the class Oligoflexia was shown to harbour environmental clones or phylotypes of uncultured or "not-yet-cultured" bacteria from various sources. Table 2 shows a set of sequence information of 20 phylotypes, which are selected from clone libraries consisting of PCR-amplified near-full-length 16S rRNA gene sequences registered in DDBJ/EMBL/GenBank databases (partly published). Their isolation sources are ranging from soils to cyanobacterial mat, bio-filter, human skin, ant colony, desert, glacial ice, earthworm intestine and seawater (Table 2). This implicates that the class Oligoflexia hosts a variety of not-yet-cultured bacterial species occurring in wide-ranging habitats.

So far, the closest phylotype to the O. tunisiensis $16 \mathrm{~S}$ rRNA gene sequence has been TSBAR001_G23 acession no. AB486128; (Table 2) with a similarity of $98.3 \%$. The phylotype was found in a clone library constructed from a Japanese paddy field microflora, and its

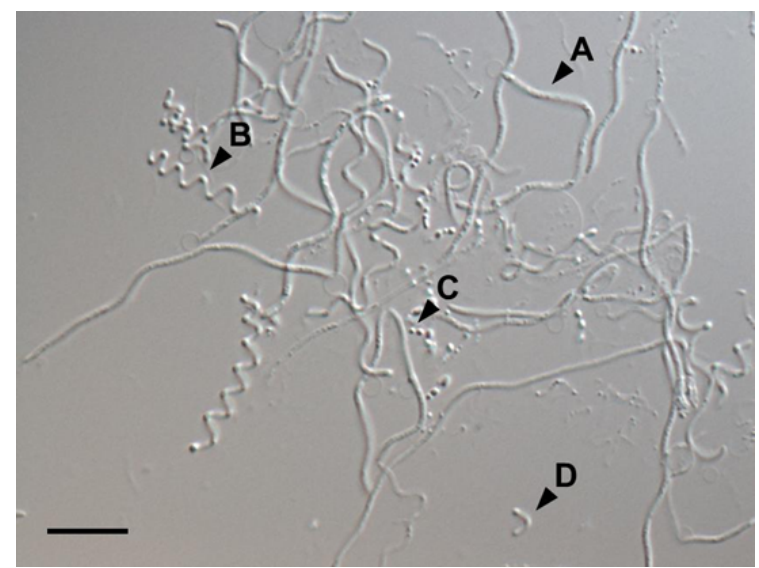

Figure 1: Micrograph of Oligoflexus tunisiensis cells

The cells exhibited a (A) slender filamentous, (B) spiral, (C) spherical (or curled), or (D) curved rod morphology. Scale bar, $10 \mu \mathrm{m}$. occurrence frequency was as low as $1 / 1036$, i.e., only one out of total 1036 clones [16]. The paddy field soil was added experimentally with nitrate (in reference to nitrate reduction) and yielded the emerging clone TSNIR001_J18 (AB487112; 16) that is only distantly related to O. tunisiensis at $84.6 \%$ similarity but within the Oligoflexia cluster. The emerging clone may have been associated with nitrate reduction. On the other hand, O. tunisiensis shows no nitrate reduction activity with a phenotypic test using API 20NE kit (bioMérieux) [9]. Nonetheless, involvement of the Oligoflexia members in nitrate cycling should be surveyed.

In contrast to their wide-ranging sources, Oligoflexia-affiliated clones are rarely found in many clone libraries. For example, no Oligoflexia clones are seen in a soil clone library (consisting of 1700 clones of PCR-amplified near-full-length 16S rRNA gene sequences), $32 \%$ of which are affiliated with the phylum Proteobacteria [17]. Another soil clone library (consisting of 13,001 clones) focusing on "rare members of the soil biosphere" yielded no Oligoflexia clones, either [18]. Thus, Oligoflexia-affiliated bacteria are likely very minor in soils, and their biogeochemical importance may be low accordingly. Yet, quantitative techniques such as real-time PCR and cell counting with fluorescence in situ hybridization are needed to quantify the occurrences of Oligoflexia-affiliated bacteria in environments.

There have been six phylotypes so far that show $>97 \%$ similarities with the O. tunisiensis $16 \mathrm{~S}$ rRNA gene sequence (Table 2). They are second to seventh closest to and presumably regarded as the same species as $O$. tunisiensis. The second to fifth closest phylotypes are from a lacustrine cyanobacterial mat in China and a microalgal photobioreactor in Germany; the latter yielded an occurrence frequency of 3/171 [19], which suggests co-occurrence relationship between $O$. tunisiensis and phototrophs. The sixth and seventh closest phylotypes were obtained from a bio-filter in China and from American children's knee-pit skin, respectively. Combining with the phylotypes to the tenth closest, occurrence of the O. tunisiensis kins extend to wider habitats (Table 2).

Previous affiliations of certain clones were revised to be members of the class Oligoflexia. The clones' glb351c (EU978839) and glb342c (EU978830) were obtained from glacial ice if the Northern Schneeferner in Germany, and originally affiliated with the classes Deltaproteobacteria and Betaproteobacteria, respectively [20]: the glacial phylotypes are now re-affiliated with the class Oligoflexia [9]. Although their similarities are as only $89.8 \%$ and $87.1 \%$, respectively, to the O. tunisiensis $16 \mathrm{~S}$ rRNA gene sequence (Table 2), but they are still placed within the Oligoflexia cluster.

The original clone library of the glacial clones consisted of 338 near-full-length clones, dominated by Proteobacteria phylotypes at a frequency of $190 / 338$, most of which were affiliated with the class Betaproteobacteria [20]. The Betaproteobacteria dominance has commonly been evident in other microflorae of cold habitats such as glacial ice [21], alpine snow [22] and sub-glacial sediment [23]. In contrast, no phylotypes were affiliated to Oligoflexia from these cold habitats (Table 2), and only the few clones were seen at a frequency as low as 4/338 of the German glacier clones [20].Additionally, the glacier phylotype glb351c and the earthworm intestine clone A0205D (FJ542822) [24] show a 97.0\% similarity and form a small but monophyletic cluster [9]. This close relationship leads to an idea that the phylotypes may not be specific to cold habitats.

Recent development of high-throughput sequencing has enabled extensive metagenomic analyses of environmental microorganisms $[25,26]$, as well as massive analyses of $16 \mathrm{~S}$ rRNA gene sequences 
Citation: Nakai R, Naganuma T (2015) Oligoflexia, the Newest Class of the Phylum Proteobacteria, Consisting of only One Cultured Species and Uncultured Bacterial Phylotypes from Diverse Habitats. J Phylogen Evolution Biol 3: 141. doi:10.4172/2329-9002.1000141

Table 1: Morphological and phenotypic traits of Oligoflexus tunisiensis.

\begin{tabular}{|l|l|}
\hline Characteristic & O. tunisiensis \\
\hline Cell morphology & $\begin{array}{l}\text { Mainly slender filamentous, but some exhibited a spiral, spherical (or curled), or } \\
\text { curved rod form (see, Figure 1) }\end{array}$ \\
\hline Cell width $(\mu \mathrm{m})$ & $0.4-0.8$ \\
\hline Growth Conditions & \\
\hline Temperature $\left({ }^{\circ} \mathrm{C}\right)$ & $20-37$ (optimal range, 25-30) \\
\hline $\mathrm{NaCl}$ concentration $(\%)$ & $<1.0$ \\
\hline $\mathrm{pH}$ & $7.0-9.5$ (optimal range, $7.0-8.0)$ \\
\hline Dominant cellular fatty acid & $\mathrm{C}_{16: 1 \omega 5 c^{\prime}} \mathrm{C}_{16: 0}$ \\
\hline Major respiratory quinone & menaquinone-7 (MK-7) \\
\hline DNA G+C content (mol\%) & 54.0 \\
\hline Positive enzyme activities & \\
\hline Esterase lipase, leucine arylamidase, naphthol-AS-Bl-phosphohydrolase, & \\
\hline protease (gelatinase), trypsin, $\alpha-m a n n o s i d a s e$ & \\
\hline Data from Nakai et al. $(2014)$ & \\
\hline
\end{tabular}

Table 2: Isolation source of environmentally-derived 16S rRNA gene sequences, a.k.a. environmental clones or phylotypes, within the class Oligoflexia

\begin{tabular}{|c|c|c|c|c|c|c|}
\hline Phylotype & Accession no. & Identity $(\%)^{a}$ & $\begin{array}{l}\text { Alignment length } \\
\text { (bp) }^{\mathrm{a}}\end{array}$ & Isolation source & $\begin{array}{l}\text { Detection } \\
\text { frequency in } \\
\text { clone library }\end{array}$ & Reference \\
\hline clone TSBAR001_G23 & AB486128 & 98.3 & 1374 & rice paddy soil & $1 / 1036$ & {$[16]$} \\
\hline clone E21 & HQ827927 & 97.7 & 1413 & $\begin{array}{l}\text { cyanobacterial blooms in a } \\
\text { hypereutrophic lake }\end{array}$ & $-\mathrm{b}$ & unpublished \\
\hline clone BF 006 & KC994686 & 97.5 & 1458 & microalgae photobioreactor & $1 / 171$ & [19] \\
\hline clone BF 004 & KC994684 & 97.5 & 1458 & microalgae photobioreactor & $1 / 171$ & [19] \\
\hline clone BF 014 & KC994694 & 97.5 & 1458 & microalgae photobioreactor & $1 / 171$ & [19] \\
\hline clone V201-58 & HQ114073 & 97.4 & 1455 & biofilm in a vermifilter & - & unpublished \\
\hline clone ncd2130c10c1 & JF183716 & 97.2 & 1354 & skin (popliteal fossa) & $N^{c}$ & [31] \\
\hline clone H-169 & HM565023 & 96.6 & 1460 & concrete & - & unpublished \\
\hline $\begin{array}{l}\text { clone SINZ1495_ } \\
\text { N11D4_16S_B }\end{array}$ & LN563658 & 96.2 & 1365 & refuse dumps of leafcutter ant & - & unpublished \\
\hline clone ncd2100g03c1 & JF181808 & 95.9 & 1356 & skin (volar forearm) & ND & [31] \\
\hline clone T5CLN43 & AB696523 & 90.8 & 1461 & Taklamakan desert soil & - & unpublished \\
\hline clone glb351c & EU978839 & 89.8 & 1463 & glacier ice & $3 / 338$ & [20] \\
\hline clone Elev_16S_1354 & EF019970 & 89.7 & 1369 & trembling aspen rhizosphere & $<1 \%$ & [32] \\
\hline clone Dok52 & FJ710772 & 89.6 & 1457 & anaerobic ammonium oxidation reactor & - & unpublished \\
\hline clone A02-05D & FJ542822 & 89.5 & 1461 & earthworm gut & $1 / 105$ & [24] \\
\hline clone glb342c & EU978830 & 87.1 & 1461 & glacier ice & $1 / 338$ & [20] \\
\hline clone SHWH_night1_16S_626 & FJ744863 & 86.3 & 1374 & surface seawater & ND & [33] \\
\hline clone UA24 & DQ269039 & 85.6 & 1413 & surface of marine macro-alga & - & unpublished \\
\hline clone FCPS531 & EF516682 & 85.5 & 1443 & grassland soil & ND & [30] \\
\hline clone TSNIR001_J18 & AB487112 & 84.6 & 1382 & rice paddy soil & $1 / 1064$ & {$[16]$} \\
\hline
\end{tabular}

Data are from the phylogenetic tree for the phylum Proteobacteria described in Nakai et al. (2014) and a BLASTN search dated October 2014

a The sequence identity and its alignment length to 16S rRNA gene sequence of Oligoflexus tunisiensis (acession no. AB540021)

b-: unknown

${ }^{c}$ ND: no description 
Citation: Nakai R, Naganuma T (2015) Oligoflexia, the Newest Class of the Phylum Proteobacteria, Consisting of only One Cultured Species and Uncultured Bacterial Phylotypes from Diverse Habitats. J Phylogen Evolution Biol 3: 141. doi:10.4172/2329-9002.1000141

derived from environmental samples [27]. Then, we have conducted an extensive database search on Meta-Metagenomic DataBase (MetaMetaDB; http://mmdb.aori.u-tokyo.ac.jp/) [28], which contained $2,737,833$ sequences (shorter than $300-500$ bp generated by 454-pyrosequencing) of $16 \mathrm{~S}$ rRNA genes from 61 environments (as of October 2014).

The database search showed that the O. tunisiensis $16 \mathrm{~S}$ rRNA gene sequence matches with 5,11, 106 and 1198 sequences at 97\%, 95\%, $90 \%$ and $85 \%$ similarities, respectively. If $85 \%$-similarity outlines the Oligoflexia cluster, the number of matched sequences (1198) accounts for ca. $0.04 \%$ of total MetaMetaDB sequences $(2,737,833)$.

The MetaMetaDB also provides a "habitability index" (Figure 2) to infer possible habitats of a queried sequence or a "query" and its related sequences [28] based on the BLASTN search [29]. The result suggested that the $>97 \%$-similar sequences (to the O. tunisiensis $16 \mathrm{~S}$ rRNA gene sequence) were likely from rhizosphere, while $<95 \%$-similar sequences were mostly from underground habitats such as groundwater and hydrocarbon (e.g. petroleum and gas) reservoir. Figure 2 illustrates "habitability indices" as percentages for source habitats of the matched sequences. Certain geographical tendencies of the source habitats are shown, despite phylogenetic limitation due to short lengths (less than $300-500 \mathrm{bp}$ ) of the sequences generated by 454 -pyrosequencing.

In summary, general features of the phylotypes (clones) and partial sequences affiliated with the class Oligoflexia are: 1) that they are derived from a variety of source habitats, suggestive of cosmopolite distribution; and 2) that they are minor in occurrence frequencies, possibly associated with the slow-growing nature of the type species, O. tunisiensis. An emerging character is "cosmopolite but minor" or "minor cosmopolitan", which should be tested with other Oligoflexia species to be cultured in future studies.

\section{Acknowledgements}

We thank Dr. Miyuki Nishijima, TechnoSuruga Laboratory Co., Ltd., for helpful discussions. R. N. was supported by a JSPS Research Fellowship for Young Scientists (no. 13J03441). This work was partially supported by a Grant for Basic Science Research Projects from the Sumitomo Foundation (no. 130894).

\section{References}

1. Kersters K, De Vos P, Gillis M, Swings J, Vandamme P, et al. (2006) Introduction to the Proteobacteria. Dwarkin M, Falkow S, Rosenberg E, Schleifer K-H, Stackebrandt (editors). The Prokaryotes, 3rd edition, volume 5, Springer, NewYork, USA, 3-37.

2. Rinke C, Schwientek P, Sczyrba A, Ivanova NN, Anderson IJ, et al. (2013) Insights into the phylogeny and coding potential of microbial dark matter. Nature 499: 431-437

3. Janssen PH (2006) Identifying the dominant soil bacterial taxa in libraries of 16S rRNA and 16S rRNA genes. Appl Environ Microbiol 72: 1719-1728.

4. Spain AM, Krumholz LR, Elshahed MS (2009) Abundance, composition, diversity and novelty of soil Proteobacteria. ISME J 3: 992-1000.

5. Woese CR (1987) Bacterial evolution. Microbiol Rev 51: 221-271.

6. Garrity GM, Bell JA, Lilburn T (2005) Phylum XIV. Proteobacteria phyl. nov. Bergey's Manual of Systematic Bacteriology, 2nd edition. Brenner DJ, Krieg NR, Staley JT, Garrity GM (editors), volume 2, Springer, New York, USA.

7. Emerson D, Rentz JA, Lilburn TG, Davis RE, Aldrich H, et al. (2007) A novel lineage of proteobacteria involved in formation of marine Fe-oxidizing microbial mat communities. PLoS One 2: e667.

8. Williams KP, Kelly DP (2013) Proposal for a new class within the phylum Proteobacteria, Acidithiobacillia classis nov., with the type order Acidithiobacillales, and emended description of the class Gammaproteobacteria. Int J Syst Evol Microbiol 63: 2901-2906.

9. Nakai R, Nishijima M, Tazato N, Handa Y, Karray F, et al. (2014) Oligoflexus tunisiensis gen. nov., sp. nov., a Gram-negative, aerobic, filamentous bacterium

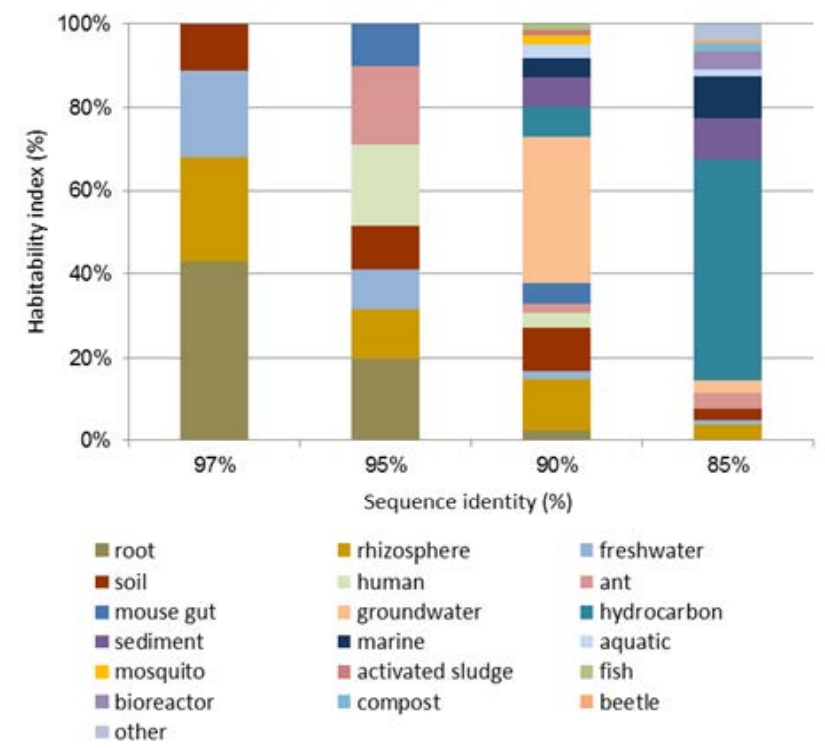

Figure 2: Inferred source habitats for partial 16S rRNA gene sequences of notyet-cultured bacteria potentially affiliated with the class Oligoflexia The microbial habitability indices ( $y$-axis) calculated using MetaMetaDB were based on a set of normalized ratios of environmental categories among the significant hits exhibiting greater than $97 \%, 95 \%, 90 \%$, and $85 \%$ identity from the BLASTN search with the 16S rRNA gene sequence of Oligoflexus tunisiensis (accession no. AB540021) against curated metagenomic sequences in MetaMetaDB.

of a novel proteobacterial lineage, and description of Oligoflexaceae fam. nov. Oligoflexales ord. nov. and Oligoflexia classis nov. Int J Syst Evol Microbiol 64: 3353-3359.

10. Hahn MW (2004) Broad diversity of viable bacteria in 'sterile' $(0.2 \mu \mathrm{m})$ filtered water. Res Microbiol 155: 688-691.

11. Geissinger O, Herlemann DP, Mörschel E, Maier UG, Brune A (2009) The ultramicrobacterium "Elusimicrobium minutum" gen. nov., sp. nov., the firs cultivated representative of the termite group 1 phylum. Appl Environ Microbiol 75: $2831-2840$.

12. Kearns DB, Venot A Bonner PJ Stevens B Boons GJ, et al (2001) Identification of a developmental chemoattractant in Myxococcus xanthus through metabolic engineering. Proc Natl Acad Sci U S A 98: 13990-13994.

13. Shimkets LJ, Dworkin M, Reichenbach H (2006) The myxobacteria. In Dworkin M, Falkow S, Rosenberg E, Schleifer K-H, Stackebrandt E (editors). The Prokaryotes, 3rd edition, volume 7. Springer, New York, USA, 31-115.

14. Elvert M, Boetius A, Knittel K, Jorgensen BB (2003) Characterization of specific membrane fatty acids as chemotaxonomic markers for sulfate-reducing bacteria involved in anaerobic oxidation of methane. Geomicrobiol J 20: 403-419.

15. Boetius A, Ravenschlag K, Schubert CJ, Rickert D, Widdel F, et al. (2000) A marine microbial consortium apparently mediating anaerobic oxidation of methane. Nature 407: 623-626.

16. Ishii S, Yamamoto M, Kikuchi M, Oshima K, Hattori M, et al. (2009) Microbia populations responsive to denitrification-inducing conditions in rice paddy soil, as revealed by comparative $16 \mathrm{~S}$ rRNA gene analysis. Appl Environ Microbiol 75: 7070-7078.

17. Tringe SG, von Mering C, Kobayashi A, Salamov AA, Chen K, et al. (2005) Comparative metagenomics of microbial communities. Science 308: 554-557.

18. Elshahed MS, Youssef NH, Spain AM, Sheik C, Najar FZ, et al. (2008) Novelty and uniqueness patterns of rare members of the soil biosphere. Appl Environ Microbiol 74: 5422-5428.

19. Krohn-Molt I, Wemheuer B, Alawi M, Poehlein A, Güllert S, et al. (2013) Metagenome survey of a multispecies and alga-associated biofilm revealed key elements of bacterial-algal interactions in photobioreactors. Appl Environ Microbiol 79: 6196-6206. 
Citation: Nakai R, Naganuma T (2015) Oligoflexia, the Newest Class of the Phylum Proteobacteria, Consisting of only One Cultured Species and Uncultured Bacterial Phylotypes from Diverse Habitats. J Phylogen Evolution Biol 3: 141. doi:10.4172/2329-9002.1000141

20. Simon C, Wiezer A, Strittmatter AW, Daniel R (2009) Phylogenetic diversity and metabolic potential revealed in a glacier ice metagenome. Appl Environ Microbiol 75: 7519-7526.

21. Foght J, Aislabie J, Turner S, Brown CE, Ryburn J, et al. (2004) Culturable bacteria in subglacial sediments and ice from two Southern Hemisphere glaciers. Microb Ecol 47: 329-340.

22. Segawa T1, Miyamoto K, Ushida K, Agata K, Okada N, et al. (2005) Seasonal change in bacterial flora and biomass in mountain snow from the Tateyama Mountains, Japan, analyzed by $16 \mathrm{~S}$ rRNA gene sequencing and real-time PCR. Appl Environ Microbiol 71: 123-130.

23. Cheng SM, Foght JM (2007) Cultivation-independent and -dependent characterization of Bacteria resident beneath John Evans Glacier. FEMS Microbiol Ecol 59: 318-330.

24. Rattray RM, Perumbakkam S, Smith F, Craig AM (2010) Microbiomic comparison of the intestine of the earthworm Eisenia fetida fed ergovaline. Curr Microbiol 60: 229-235.

25. Hugenholtz P, Tyson GW (2008) Microbiology: metagenomics. Nature 455 481-483.

26. Bragg L, Tyson GW (2014) Metagenomics using next-generation sequencing Methods Mol Biol 1096: 183-201.
27. Logares R, Sunagawa S, Salazar G, Cornejo-Castillo FM, Ferrera I, et al. (2014) Metagenomic $16 \mathrm{~S}$ rDNA Illumina tags are a powerful alternative to amplicon sequencing to explore diversity and structure of microbial communities. Environ Microbiol 16: 2659-2671.

28. Yang CC, Iwasaki W (2014) MetaMetaDB: a database and analytic system for investigating microbial habitability. PLoS One 9: e87126.

29. Camacho C, Coulouris G, Avagyan V, Ma N, Papadopoulos J, et al. (2009) BLAST+: architecture and applications. BMC Bioinformatics 10: 421.

30. Cruz-Martínez K, Suttle KB, Brodie EL, Power ME, Andersen GL, et al. (2009) Despite strong seasonal responses, soil microbial consortia are more resilient to long-term changes in rainfall than overlying grassland. ISME J 3: 738-744.

31. Kong HH, Oh J, Deming C, Conlan S, Grice EA, et al. (2012) Temporal shifts in the skin microbiome associated with disease flares and treatment in children with atopic dermatitis. Genome Res 22: 850-859.

32. Lesaulnier C, Papamichail D, McCorkle S, Ollivier B, Skiena S, et al. (2008) Elevated atmospheric $\mathrm{CO}_{2}$ affects soil microbial diversity associated with trembling aspen. Environ Microbiol 10: 926-941.

33. Poretsky RS, Sun S, Mou X, Moran MA (2010) Transporter genes expressed by coastal bacterioplankton in response to dissolved organic carbon. Environ Microbiol 12: 616-627. 